\title{
Dismantling the social safety net: social security reforms, disability and mental health conditions
}

\author{
Jed Boardman (1)
}

BJPsych Bulletin (2020) 44, 208-212, doi:10.1192/bjb.2020.79

Institute of Psychiatry, Psychology \& Neuroscience, King's College London, UK

Correspondence to Jed Boardman (jedboard@atlas.co.uk)

First received 20 Feb 2020, final revision 6 Jun 2020, accepted 10 Jun 2020

(c) The Authors 2020. This is an Open Access article, distributed under the terms of the Creative Commons

Attribution-NonCommercial-ShareAlike licence (http://creativecommons.org/ licenses/by-nc-sa/4.0/), which permits non-commercial re-use, distribution, and reproduction in any medium, provided the same Creative Commons licence is included and the original work is properly cited. The written permission of Cambridge University Press must be obtained for commercial re-use.
Summary This article examines the effects of UK welfare reform since 2008 on people with mental health conditions and disabilities. The results have been profound, particularly during a time of economic austerity, damaging the social safety net and pushing many vulnerable people into poverty and hardship. It has perpetuated inequalities and increased the social exclusion of disabled groups. The holes in the safety net require repair, alongside extensive social policy reform to both protect and empower people with disabilities and long-term conditions.

Keywords Mental health conditions; welfare reforms; disability; sickness; social policy.
In his report following a visit to the UK in 2018, the UN special rapporteur on extreme poverty and human rights, Philip Alston, said that 'the social safety net has been damaged by drastic cuts' and that the net 'has been systematically and starkly eroded, particularly since 2010'. ${ }^{1}$ His report highlighted the effects of social service cuts, welfare reforms and austerity on poverty in the UK. This followed comments by the UN's Committee on the Rights of Persons with Disabilities that the welfare reforms had led to 'grave and systematic' violations of disabled peoples' rights. ${ }^{2}$

I examine here the results that this damage to the safety net has had on people with disabilities and mental health conditions in the UK with reference to the changes in welfare benefits that have taken place over the past 12 years.

\section{Disabilities and mental health conditions}

I have chosen to examine the effect of UK welfare reforms across all disability groups for several reasons. The first of these is practical, as many official statistics do not separate people with disabilities into those with mental or with physical problems. The groups of people and their conditions that are contained in the category of 'disability' is fluid and has changed over time. ${ }^{3}$ Recent shifts have broadened the scope, adding people with mental health conditions, intellectual disabilities, developmental disorders and sensory impairments. This is reflected in our anti-discrimination laws: the Equality Act 2010 defines disability as 'a physical or mental impairment which has a substantial and long-term adverse effect on the ability to carry out normal day-to-day activities'. The terminology is also reflected in the term 'long-term conditions', which applies to many of the people who are receiving sickness and disability benefits and are commonly users of health and social services. People with long-term mental health conditions are likely to be: living in households below the poverty threshold, to be in debt or have financial problems, to be in receipt of benefits, to be without a paid job and to live in social housing, and they are about three times more likely to have multiple social disadvantages than the general population. ${ }^{4}$ Many people who have mental or physical disabilities are on low incomes, they share common difficulties and are vulnerable to the effects of benefit changes.

\section{Welfare reforms in the 21st century}

The provision of services and income transfers by the state to meet the welfare needs of the UK population and the concomitant expenditure grew in the 20th century. These provisions include personal social services, services for healthcare, education and housing and income transfers such as pensions and out of work payments. One function of the welfare state is to protect people in times of hardship.

Most agree that the golden age of the British welfare state occurred after the Second World War, with rapid reforms to create a more comprehensive and universal 
welfare state with an increase in resources to extend benefits and coverage. ${ }^{5}$ This was associated with a commitment to economic growth and full employment. The development of the modern welfare state has been a driver for the improvements in provisions for people with disabilities, including those for people with mental health conditions and intellectual disabilities. ${ }^{6}$

The golden age declined in the 1970s, and the 1980s saw a period of retrenchment and recalibration, with an abandonment of full employment and cuts to welfare provision, despite continuing growth in public expenditure. ${ }^{5}$ This was set against a background of increasing income and wealth inequality. In the late 1990s and most of the 2000s, the New Labour government's vision for welfare was for a system that enabled rather than provided. The challenge was to reduce worklessness and introduce new benefits and tax credits as well as introducing work support schemes. The recession in 2008 and the election of the coalition government in 2010 brought in a period of austerity and the introduction of further welfare reforms in 2012. The squeeze on expenditure and the roll out of the new benefits continue to this day, and the welfare state may face further retrenchment following the COVID-19 pandemic.

\section{Changes in sickness and disability benefits}

The two main direct payment benefits that are specifically aimed at people with ill health and disability are those that provide out of work payments (Employment and Support Allowance - ESA) and those that cover the extra costs of disability (Personal Independence Payment - PIP). ${ }^{7}$

ESA was introduced in 2008 as a result of the Welfare Reform Act 2007 and replaced Incapacity Benefit. Claimants for ESA are assessed through the process of the Work Capability Assessment (WCA) that includes face-to-face contact with a clinical assessor, who determines their ability to manage a variety of daily activities (physical and mental). The WCA process assesses whether a person is entitled to ESA based on their 'limited capability for work' (LCW) and their 'limited capacity for work-related activity' (LCWA). Those found to have LCW and not LCWA are placed in the work-related activities group (WRAG) and are expected to engage with job centre staff in seeking work. Those found to have LCW and LCWA are placed in the Support Group and are not expected to engage with work-related activity. For those in the WRAG, failure to engage with Job Centre staff can result in sanctions that may reduce or suspend benefit payments.

PIP, designed to replace the Disability Living Allowance (DLA) for people 16 years of age and over, was introduced as part of a range of benefit changes in the Welfare Reform Act 2012. Assessments for PIP, unlike those for DLA, are done by face-to-face interviews with a clinical assessor. Payment is given depending on the degree of difficulties experienced in activities of daily living and mobility.

Although these benefits represent the main direct payment to people with a range of disabilities, the 2012 Act also introduced further changes that have a significant effect on people with low incomes. These include: Universal Credit, the under-occupancy charge ('bedroom tax'), a benefit cap and the up-rating of local housing allowance rates by the Consumer Price Index.

Universal Credit was introduced in an attempt to simplify the delivery of benefits and is a single monthly payment that applies to people who are looking for work or are on a low income. It brings together six working-age benefits: ESA, along with the income-based Jobseeker's Allowance, Income Support, Child Tax Credits, Working Tax Credits and Housing Benefit. It rapidly hit the headlines because of its delayed payments, and its full roll-out has been delayed. ${ }^{8}$

\section{Disability and poverty}

Changes to the welfare state have effects on almost the entire population, but it is those on low incomes that are often disproportionately affected. ${ }^{9}$ This includes many with mental health conditions and disabilities. The latest figures on poverty in the UK (2017-2018) show that, of the 14 million people who live in poverty, 4 million have a disability and a further 3 million live with someone who has a disability. An estimated 13 million adults and children in the UK have a disability, $31 \%$ of whom live in poverty (the poverty rate among the non-disabled population is 20\%). Nearly half of those who are disabled have a disability due to a mental health condition - for this group the poverty rate is $39 \%$, compared with $30 \%$ among those with a physical disability. ${ }^{10}$ These figures have changed little over the past 8 years.

These figures reinforce the UN rapporteur's findings and point to a significant number of people with disabilities falling through the poverty safety net. It seems that benefits may not necessarily protect people with disabilities from falling into poverty.

\section{Financial impact of welfare reforms on people with disabilities}

Since 2012, organisations have warned about the impact of the cuts in benefits on people with long-term conditions. ${ }^{11,12}$ Recent economic modelling examining the impact of the benefit changes since 2008 shows that disabled people have lost, on average, $£ 1200$ each year, compared with $£ 300$ for non-disabled people. ${ }^{13}$ The benefit changes have most impact on those with intellectual disabilities, social interaction difficulties and mental health conditions.

\section{Problems with benefit assessments}

From the start of its implementation, the WCA process was reported to present difficulties for those being assessed. The Citizens Advice Bureau (CAB) reported that the assessment was not effectively measuring fitness for work, often ignored independent clinical evidence and was producing inappropriate outcomes. ${ }^{14,15}$ Claimants reported rushed assessments, inaccurate recording of their accounts and poor recognition of mental health problems. ${ }^{14}$ Many people report the process to be anxiety-provoking and a cause of deterioration in their health. The WCA remains widely condemned and seen in need of review. ${ }^{16,17}$ Official Department for 
Work and Pensions (DWP) reviews of the WCA have questioned whether descriptors are fit for purpose and whether the assessment is sufficiently fair and effective. ${ }^{18}$

The Court of Appeal in 2013 judged the WCA to substantially disadvantage people with mental health problems and said that the DWP had failed to make reasonable adjustments to ensure that people with mental health problems were treated fairly by the system. ${ }^{19}$ Disadvantages for people with mental health conditions include: finding it difficult to report on the nature of their condition or the way that it affects their functioning; difficulty in attending for interviews or expressing themselves at interview; the fluctuating nature of their conditions, symptoms, impairments and functioning, which may be difficult to describe or to assess; the subjective nature of many mental health conditions; and the presence of coexisting physical health conditions.

The actual rate of incorrect decisions made at ESA and PIP assessments is not known. People can appeal their ESA and PIP decisions, but first they must ask for a mandatory reconsideration from the DWP. Few of these mandatory reconsiderations lead to a change in the award (around $15 \%$ for PIP). However, for those who go on to be seen by an independent appeals panel, the majority win their appeals. In 2019, 73\% of ESA appeals and $68 \%$ of PIP appeals were won by the appellant. ${ }^{20}$

The failure of the WCA and the assessments for PIP to reliably identify those who are eligible for benefits is costly, not only in financial terms but also in human terms. ${ }^{21}$ Removal of benefits is experienced by claimants as rejection, with applicants feeling mistrusted and invisible, coupled with the stress of being in a cycle of assessments, rejections and appeals. ${ }^{22}$ People describe experiences of their difficulties being trivialised or seen as fraudulent. Overall, people with mental health conditions are relatively disadvantaged when applying for PIP. For people transferring from DLA, the likelihood of being found not entitled to PIP was almost two and a half times greater among people with mental health conditions than among claimants with physical disorders. ${ }^{23}$

Many anomalies with the specific details of the assessments for PIP and ESA have been dealt with through the court system. In 2017, the High Court quashed the new government PIP regulations for mobility activities as they discriminated against people with mental health difficulties. ${ }^{24}$ In 2019, the Supreme Court ruled on the scope of the term 'social support' in relation to the PIP activity of 'engaging with others'. ${ }^{25}$ In 2020, the Court of Appeal upheld two successful High Court challenges brought by individuals and found that the government had unlawfully discriminated against people with severe disabilities who had moved onto Universal Credit. ${ }^{26}$

One high-profile result of the financial insecurity experienced by people on welfare benefits is the rise of food banks in the UK. Prior to the current COVID-19 pandemic, many of the people using food banks were those who had been affected by the recent welfare reforms, particularly those with disabilities, lone parents and large family households. A large-scale survey of people using food banks in 20162017 found that two-thirds had a health condition and almost one-third had a mental health condition. ${ }^{27}$ Half of the households included someone with a disability - these households were three times more likely to use foodbanks than other low-income households.

Perhaps the most serious outcome of the WCA process is its relationship to suicide. It is known that the occurrence of completed suicide increases during recessions, but there is also good evidence that the government's programme of reassessing for ESA is independently associated with an increase in suicides. ${ }^{28}$ There are also several case reports of the deaths of people by suicide or neglect whose benefits had been removed, ${ }^{29}$ including the death of Errol Graham, a man with long-term mental health problems. ${ }^{30}$

A recent report from the National Audit Office ${ }^{31}$ has revealed 69 suicides linked to the DWP's handling of benefit claims in the past 6 years. This is likely to be an underestimate, as the information held by the DWP on suicides is not exhaustive. The DWP is looking to improve the data collection and review process.

\section{Conditionality and sanctions}

The principle of conditionality (the attachment of behavioural conditions to the receipt of benefits) has long been part of welfare policy. It was, however, usually applied to recipients of unemployment benefits, who were expected to seek work. This has now changed, and under ESA regulations, conditionality is applied to sick and disabled people, many of whom are expected to engage in 'work-related activity' and who may receive sanctions, including the reduction of benefits, if they do not. The aim of conditionality for these groups is to help move people off sickness benefits into work. This has been combined with schemes to support people into work, such as the Pathways to Work and Work Programme schemes. The use of conditionality is widely debated and, as a policy, it ignores the barriers that people with disabilities face in getting into employment. ${ }^{32,33}$ It is unpopular, often regarded as punitive, undermines social citizenship, is ineffective in moving people into work and can damage people's health, thus making employment less likely. ${ }^{34-37}$ Disabled unemployment claimants are more likely to be sanctioned than non-disabled claimants. ${ }^{34}$

\section{Benefit stigma}

Not only do people with disabilities associated with physical and mental conditions experience prejudice and discrimination linked to their conditions, they may also experience the stigma associated with claiming benefits and the shame associated with poverty. Overall, the UK public have low levels of understanding of the benefits system and people see the bulk of what the welfare state does as providing handouts to those who do not work..$^{9,39}$ The largest proportion of the UK welfare budget is spent on pensions (42\%), with $1 \%$ spent on unemployment benefits and $10 \%$ on incapacity, disability and injury benefits. ${ }^{40}$ Overall, the public's impression is one of a system involving 'Them and Us'. These dichotomies have pervaded the language of welfare. Traditionally, for the poor the division is between the 'deserving' and the 'undeserving' poor. In contemporary government policy. the rhetoric has been one of 'a culture of welfare dependency', 'making work pay', 'scroungers', 
'benefit cheats' and the 'hard-working majority', which has been reinforced by newspaper headlines and television programmes such as Benefits Street. It appears that in the 21st century we have shifted our gaze from the 'deserving' and 'undeserving' to 'strivers' and 'shirkers'.

\section{Effects on health and social services}

Several recent reports have shown that dealing with people's benefit problems is putting increased pressure on mental health services and benefit and financial advice agencies ${ }^{42,43}$. Community mental health teams are spending increased time managing patients' practical problems, including benefits, debt, housing and employment. Practitioners are aware that it is difficult to treat people's mental illness without finding solutions to their practical problems, which are in turn having a significant impact on the patients' mental health. Many of these problems require assistance beyond what can be provided by mental health practitioners, but accessing alternative forms of help and advice can be difficult, especially in the complex world of financial and welfare benefit systems. Nevertheless, access to help to resolve these practical issues is important to the patient's recovery and continuing engagement with health and social services (Box 1).

\section{Conclusions}

This article has documented some of the problems faced by people with mental health conditions and disabilities resulting from the changes that have emerged from welfare reforms instituted over the past 12 years. These changes, rather than enhancing support for people with disabilities, have been unjust and ethically unsound, undermining citizenship and damaging to peoples' health and well-being. It reinforces the extent to which many people with long-term mental health (and physical health) conditions are stigmatised and socially excluded and highlights the ways in which they are vulnerable to falling into poverty. This is not inevitable and can be changed by improving the social policies that determine our present welfare state. In narrow terms this means overhauling the current system of the

\section{Box 1 Useful information sources}

Further information about social security benefits and mental health conditions can be found on the Royal College of Psychiatrists' webpages on social inclusion (https://www. rcpsych.ac.uk/improving-care/campaigning-for-better-mentalhealth-policy/other-policy-areas/social-inclusion). Advice to clinicians regarding assisting patients in their application for benefits can also be found on those pages.

Other useful organisations are:

- Mind: https://www.mind.org.uk/

- Rethink Mental Illness: https://www.rethink.org/

- Money and Mental Health Policy Institute: https://www. moneyandmentalhealth.org/ provision of welfare benefits, starting with the ways in which people are assessed for ESA and PIP, removing sanctions for people with sickness and disability, increasing the actual benefit payments and improving the employment support offered to people on ESA. More generally, the broader aspects of welfare state provision (health, education, housing, social services) must become more sensitive to the needs of the range of people with disabilities. At present, the system appears at worst to be punitive and at best to provide an inadequate sticking plaster. The system needs to ensure that people with disabilities are not just supported but encouraged to thrive.

The welfare reforms have had a negative effect on our already stretched mental health and social care services. If we are to provide 21st century mental health services we need to acknowledge the role they play in our welfare state and in the treatment and care of people who live in the hinterlands of low income and poverty. We must also recognise the role of broader social and economic factors in the causation and exacerbation of mental ill health. At the minimum we must find ways of providing people who use services with access to good financial and welfare advice, but more broadly create a benefits system alongside health and social services that addresses the very problems that exclude many people with long-term conditions from playing an active role in society. We anticipate a further economic recession, this time with high levels of unemployment, following the COVID-19 pandemic. This may mean a further tightening of the screw for people with disabilities and long-term conditions. On the other hand, there exists a glimpse of a better world that offers the possibility of improving the social and economic environment for those vulnerable to the vicissitudes of economic, political and social forces.

\section{About the author}

Jed Boardman is a senior lecturer in social psychiatry at the Institute of Psychiatry Psychology \& Neuroscience, King's College London and the Lead for Social Inclusion at the Royal College of Psychiatrists London, UK.

\section{Declaration of interest}

None.

ICMJE forms are in the supplementary material, available online at https:// doi.org/10.1192/bjb.2020.79

\section{References}

1 Alston P. Visit to the United Kingdom of Great Britain and Northern Ireland: Report of the Special Rapporteur on Extreme Poverty and Human Rights (A/HRC/41/39/Add.1). United Nations, 2019.

2 ITV. UK cuts 'have created a human catastrophe for disabled people'. ITV News Report 24 Aug 2017 (https://wwwitv.com/news/2017-08 24/uk-cuts-have-created-a-human-catastrophe-for-disabled-people/).

3 Roulstone A. Personal Independence Payments, welfare reform and the shrinking disability category. Disabil Soc 2015; 30: 673-88.

4 Boardman J, Currie A, Killaspy H, Mezey G. Social Inclusion and Mental Health. RCPsych Publications, 2010.

5 Pierson C. Beyond the Welfare State: Beyond the Welfare State (3rd edn) Polity Press, 2006. 
6 Rose N. Historical changes in mental health practice. In Textbook of Community Mental Health (eds G Thornicroft, G Szmukler, KT Mueser, RE Drake). Oxford University Press, 2011.

7 Galloway A, Boland B, Williams G. Mental health problems, benefits and tackling discrimination. BJPsych Bull 2018; 42: 200-205.

8 Butler P. Claimants 'scared' of universal credit as full rollout delayed again. Guardian 4 Feb 2020 (https://www.theguardian.com/society/ 2020/feb/04/claimants-scared-as-full-roll-out-of-universal-credit-isdelayed-again).

9 Hills J. Good Times, Bad Times: The Welfare Myth of Them and Us. Policy Press, 2014.

10 Joseph Rowntree Foundation. UK Poverty 2019/20. Joseph Rowntree Foundation, 2020.

11 Wood C. Destination Unknown: Summer 2012. Demos, 2012.

12 Duffy S. A Fair Society? How the Cuts Target Disabled People. Centre for Welfare Reform, 2013.

13 Disability Benefits Consortium. Has Welfare Become Unfair? The Impact of Welfare Changes on Disabled People. Disability Benefits Consortium, 2019.

14 Citizens Advice Bureau. Not Working: CAB Evidence on the ESA Work Capability Assessment. CAB, 2010.

15 Citizens Advice Bureau. Right First Time? An Indicative Study of the Accuracy of ESA Work Capability Assessment Reports. CAB, 2012.

16 Dwyer $\mathrm{P}$, Jones $\mathrm{K}$, McNeill J, Scullion L, Stewart A. First Wave Findings: Disability and Conditionality (Research Report). University of York, 2016.

17 Baumberg B. A Better WCA is Possible. Demos, 2018

18 Harrington M. An Independent Review of the Work Capability Assessment - Year Three. TSO (The Stationery Office), 2012.

$19 M M \& D M, R$ (on the application of) $v$ Secretary of State for Work and Pensions [2013] EWCA Civ 1565. Available from: http://www.bailii. org/ew/cases/EWCA/Civ/2013/1565.html

20 Ministry of Justice. Tribunal Statistics Quarterly: April to June 2019. Ministry of Justice, 2019 (https://www.gov.uk/government/statistics/tribunal-statistics-quarterly-april-to-june-2019).

21 Hardest Hit Coalition. The Tipping Point: The Human and Economic Costs of Cutting Disabled People's Support. Hardest Hit Coalition, 2012.

22 Shefer G, Henderson C, Frost-Gaskin M, Pacitti R. Only making things worse: a qualitative study of the impact of wrongly removing disability benefits from people with mental illness. Community Ment Health J 2016; 52: 834-41.

23 Pybus K, Pickett KE, Prady SL, Lloyd C, Wilkinson R. Discrediting experiences: outcomes of eligibility assessments for claimants with psychiatric compared with non-psychiatric conditions transferring to personal independence payments in England. BJPsych Open 2019; 5: e19.

24 RF v Secretary of State for Work and Pensions [2017] EWHC 3375 (Admin). Available from: http://www.bailii.org/ew/cases/EWHC/ Admin/2017/3375.html.

25 Secretary of State for Work and Pensions (Appellant) v MM (Respondent) (Scotland) [2019] UKSC 34. Available from: https://www.supremecourt.uk/cases/docs/uksc-2017-0215-judgment.pdf.

26 The Queen (on the Application of TP, AR \& SXC) and Secretary of State for Work and Pensions Appellant and Equality and Human Rights Commission
[2020] EWCA Civ 37. Available from: https://www.bailii.org/ew/ cases/EWCA/Civ/2020/37.html

27 Loopstra R, Lalor D. Financial Insecurity, Food Insecurity, and Disability: The Profile of People Receiving Emergency Food Assistance from The Trussell Trust Foodbank Network in Britain. The Trussell Trust, 2017.

28 Barr B, Taylor-Robinson D, Stuckler D, Loopstra R, Reeves A Whitehead M. 'First, do no harm': are disability assessments associated with adverse trends in mental health? A longitudinal ecological study. $J$ Epidemiol Community Health 2015; 70: 339-45.

29 Ryan F. Crippled: Austerity and the Demonization of Disabled People. Verso, 2019.

30 Butler P. Disabled man starved to death after DWP stopped his benefits. Guardian, 28 Jan 2020 (https://www.theguardian.com/society/ 2020/jan/28/disabled-man-starved-to-death-after-dwp-stopped-hisbenefits).

31 Comptroller and Auditor General. Information Held by the Department for Work \& Pensions on Deaths by Suicide of Benefit Claimants. National Audit Office, 2020

32 Dwyer P. Punitive and ineffective: benefit sanctions within social security. J Soc Secur Law 2018; 25: 142-57.

33 Patrick RD. The wrong prescription: disabled people and welfare conditionality. Policy Polit 2011; 39: 275-91.

34 Baumberg B. Benefits conditionality for disabled people: stylized facts from a review of international evidence and practice. J Poverty Soc Justice 2017; 25: 107-28.

35 Dwyer $\mathrm{P}$, Scullion $\mathrm{L}$, Jones $\mathrm{K}, \mathrm{McNeill}$ J, Stewart ABR. Work, welfare and wellbeing? The impacts of welfare conditionality on people with mental health impairments in the UK. Soc Policy Adm 2019; 52: 311-26.

36 Weston K. Debating conditionality for disability benefits recipients and welfare reform: research evidence from Pathways to Work. Local Economy 2012; 27: 514-528.

37 Reeves A, Loopstra R. 'Set up to fail'? How welfare conditionality undermines citizenship for vulnerable groups. Soc Policy Soc 2017; 16 327-38.

38 Hale C. Fulfilling Potential? ESA and the Fate of the Work-Related Activity Group. Centre for Welfare Reform, 2014.

39 Baumberg B. The stigma of claiming benefits: a quantitative study. J Soc Policy 2016; 45: 181-99.

40 Office for National Statistics. How is the Welfare Budget Spent? ONS, 2016 (https://www.ons.gov.uk/economy/governmentpublicsectorandtaxes/ publicsectorfinance/articles/howisthewelfarebudgetspent/2016-03-16)

41 Patrick R. Working on welfare: findings from a qualitative longitudinal study into the lived experiences of welfare reform in the UK. J Soc Policy 2014; 43: 705-25.

42 Clarke T. Whose Job Is It Anyway? How Mental Health Practitioners Help Navigate Financial Difficulty. Money and Mental Health Policy Institute, 2017.

43 Fairak A. The Roadblock to Recovery: How Mental Health Practitioners Deal with People's Practical Problems in England. Citizens Advice, 2018.

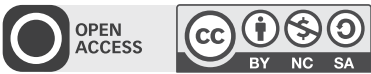

